\title{
Elevated blood pressure and headache disorders in China - associations, under-treatment and implications for public health
}

Mianwang He', Shengyuan Yu ${ }^{1 *}$, Ruozhuo Liu', Xiaosu Yang², Gang Zhao ${ }^{3}$, Xiangyang Qiao ${ }^{4}$, Jiachun Feng ${ }^{5}$, Yannan Fang ${ }^{6}$, Xiutang $\mathrm{Cao}^{7}$ and Timothy J. Steiner ${ }^{8}$

\begin{abstract}
Background: Both hypertension (HTN) and headache disorders are highly prevalent worldwide. Our purpose, in a nationwide study of the Chinese general population, was to evaluate any association between primary headache disorders and elevated blood pressure (eBP). We could not collect data on antihypertensive therapy, but took the view that, whatever such therapy might be taken, eBP was a sign that it was failing to meet treatment needs. Therefore, as a secondary purpose, important from the public-health perspective, we would present the prevalence of eBP (treated or not) as indicative of unmet health-care need in China.

Methods: This was a questionnaire-based nationwide cross-sectional door-to-door survey using cluster random-sampling, selecting one adult (18-65 years) per household. Headache was diagnosed by ICHD-II criteria and eBP as systolic blood pressure $\geq 140 \mathrm{mmHg}$ and/or diastolic blood pressure $\geq 90 \mathrm{mmHg}$. Chi-squared test and multivariate logistic regression analysis were used to assess the strength and significance of associations. We set significance at $P \leq 0.05$.
\end{abstract}

Results: Of 5,041 survey participants (participation rate 94.1\%), 154 were excluded because of missing BP data, leaving 4,987 for analysis [mean age: $43.6 \pm 12.8$ years; male 2,532 (mean age: $43.4 \pm 12.9$ years); female 2,455 (mean age $43.9 \pm 12.8$ years)]. There were 466 participants with migraine, 535 with tension type headache (TTH) and 48 with all causes of headache on $\geq 15$ days/month. The prevalence of eBP was $22.1 \%$ (males $22.9 \%$, females $21.3 \%$ ). No associations of eBP with any of the headache disorders survived multivariate adjusted analysis. The demographic and anthropometric variables most strongly associated with eBP were higher age (AOR 3.7) and being overweight (AOR 2.4), seen in both genders. Less strong were male gender, lower educational level and urban habitation.

Conclusions: We found no clear-cut associations between eBP and any headache disorder. The associations with demographic and anthropometric variables may have acted as confounders in past reports to the contrary. We did find an alarmingly high prevalence of eBP, recognizing that this signals substantial under-treatment in China of a serious condition, and therefore a major public-health concern.

Keywords: Headache; Hypertension; Public health; Population-based survey; China; Global campaign against headache

\footnotetext{
* Correspondence: yusy1963@126.com

'Department of Neurology, Chinese PLA General Hospital, Fuxing Road 28,

Haidian District, 100853 Beijing, China

Full list of author information is available at the end of the article
} 


\section{Background}

Both hypertension (HTN) and headache disorders are highly prevalent worldwide. HTN is recognised as a global public-health problem affecting over one quarter of adults in the world [1]. It is one of the major risk factors for cardiovascular diseases (CVDs), from which an estimated 17.3 million people worldwide die each year, a number expected to rise to 23.3 million by 2030 [2]. Thereby, inter alia, it contributes substantially to the burden of noncommunicable diseases [2], while over $80 \%$ of these deaths occur in low- and middle-income countries [2]. Active headache disorders affect $46 \%$ of adults in the world, with regional variations [3], and are the third leading cause of disability worldwide [4].

China, the most populous country in the world, appears to be no exception as far as HTN is concerned: a recent study reported an adult prevalence of $26.6 \%$ [5]. Headache disorders are somewhat less prevalent than the global mean: we found, in a nationwide population-based study, a 1-year prevalence of primary headache disorders of $23.8 \%$, of migraine $9.3 \%$, of tension-type headache (TTH) $10.8 \%$, and of all causes of headache occurring on $\geq 15$ days/month $1.0 \%$ [6]. The relatively low prevalence of migraine is reflected also in Japan [7] and Taiwan [8], and appears to be genetically determined. Even so, about a quarter of Chinese adults have a headache disorder, and a similar proportion have HTN.

The association between HTN and headache, especially primary headache, is controversial. Two studies have suggested there is no association $[9,10]$. Using ambulatory blood pressure (BP) monitoring, two studies found no association between the occurrence of headache and $\mathrm{BP}$ variation in patients with mild-to-moderate hypertension [11, 12], and no variation of BP around episodes of TTH and migraine-like headache [11]. Some studies found inverse relationships: between HTN and migraine in men [13], between BP level and migraine in the elderly [14], between BP level and migraine [15], and between systolic BP and subsequent development of headache [16]. Other studies found direct relationships between headache and prevalence of HTN, including severe migraine, TTH and other headache [17], and migraine, TTH and "chronic daily headache" [18]. Clearly, consensus is lacking.

We investigated the prevalence of primary headache disorders and possibly associated factors in a large nationwide cross-sectional survey of the Chinese population $[6,19]$, as a project within the Global Campaign against Headache [20]. One of the variables of interest was BP. In the context of this headache-specific survey we could not collect information on any antihypertensive therapy being taken, and we could not and did not seek to assess the prevalence of HTN. Instead we aimed to establish the prevalence of elevated $\mathrm{BP}(\mathrm{eBP})$, and its association with headache. This was the first populationbased study to do this in mainland China.

Additionally, we took the view that, whatever antihypertensive therapy might be taken, eBP was a sign that it was failing to meet treatment needs. Therefore, as a secondary but important purpose from the public-health perspective, we would present the prevalence of eBP (treated or not) as indicative of unmet health-care need in China.

\section{Methods}

\section{Ethics}

The study protocol was approved by the Chinese Ministry of Health and the ethics committee of the Chinese PLA General Hospital, Beijing, China.

\section{Study design}

In 2009 to 2010, we performed a cross-sectional door-todoor survey of the adult population throughout China, obtaining a representative sample of the adult population using cluster random-sampling software according to the EPI method established by the World Health Organization [12]. These methods have been described in detail elsewhere $[6,19]$. The enquiry employed a structured questionnaire developed by Lifting The Burden [20] for population-based studies, translated into Chinese from the English version and validated within the target population in a sub-study [19]. Demographic enquiry included age, gender, habitation, marital status, occupation and educational level. Headache diagnoses were based on International Classification of Headache Disorders 2nd edition (ICHD-II) criteria [21].

\section{Blood pressure measurements}

$\mathrm{BP}$ was measured twice in the sitting position after rest for at least 15 minutes using a calibrated aneroid sphygmomanometer; the mean values of systolic (SBP) and diastolic blood pressure (DBP) were taken. We defined eBP as SBP $\geq 140 \mathrm{mmHg}$ and/or DBP $\geq 90 \mathrm{mmHg}$ [22].

\section{Anthropometric measurements}

All body measurements used standard anthropometric protocols. Weight and height were recorded using a portable calibrated digital scale. Body mass index (BMI) was calculated as weight divided by square of height. We defined overweight as BMI $\geq 25.0 \mathrm{~kg} / \mathrm{m}^{2}$ as described in our previous study [23].

\section{Statistical analysis}

All demographic variables were categorized (see Table 1) and presented as percentages. Age was also expressed as means \pm standard deviations (SDs). Prevalences of headache and of eBP were estimated as percentages with $95 \%$ confidence intervals (CIs). We used independent 
Table 1 Demographic, anthropometric and blood pressure data of the sample $(N=4,987)$

\begin{tabular}{lllc}
\hline Variable & Category & Number & Percent \\
\hline Gender & Male & 2,532 & 50.8 \\
& Female & 2,455 & 49.2 \\
Age (years) & $18-39$ & 1,897 & 38.0 \\
& $40-65$ & 3,090 & 62.0 \\
Habitation & Urban & 1,574 & 31.6 \\
& Rural & 3,413 & 68.4 \\
Educational level & Secondary school or less & 3,503 & 70.2 \\
& Highschool or above & 1,484 & 29.8 \\
Marital status & Single, widowed,divorced & 681 & 13.7 \\
& Married & 4,306 & 86.3 \\
Body weight & Normal or below & 3,759 & 75.4 \\
& Overweight & 1,228 & 24.6 \\
Occupation & Unemployed & 425 & 8.5 \\
& Working (employee or other) & 4,562 & 91.5 \\
Blood pressure & Normal & 3,885 & 77.9 \\
& Elevated & 1,102 & 22.1 \\
\hline
\end{tabular}

chi-squared tests for significance of differences in primary headache prevalence between people with eBP and those without, regarding $P \leq 0.05$ as significant. We then calculated adjusted odds ratios (AORs) with $95 \%$ CIs by multivariate logistic regression taking into account the following variables: age, gender, habitation, marital status, occupation, educational level, body weight. We took the group with normal BP as the reference. We used similar methods to examine possible associations between eBP and demographic and anthropometric variables.

\section{Results}

Among the 5,041 survey participants (participation rate $94.1 \%$ [4]), 154 with missing BP data were excluded, leaving 4,987 for analysis (mean age: $43.6 \pm 12.8$ years; male 2,532 [mean age: 43.4 \pm 12.9 years]; female 2,455[mean age $43.9 \pm 12.8$ years]). There were 466 subjects with migraine, 535 with TTH and 48 with headache on $\geq 15$ days/ month. Table 1 shows the distribution of demographic and anthropometric variables in the sample, and Table 2 shows this according to headache type. The prevalence of eBP was $22.1 \%(95 \%$ CI: 20.9-23.2 \%) overall, $22.9 \%(21.2-$ $24.5 \%)$ in males and $21.3 \%(19.7-22.9 \%)$ in females.

More detailed analysis of the associations of headache with eBP, by gender, is shown in Table 3 . This sets out the estimated 1-year prevalences of migraine, TTH and all causes of headache on $\geq 15$ days/month in participants with eBP or normal BP. Overall (11.0 \% vs $8.9 \%)$, and in males (7.9\% vs. $5.3 \%)$, participants with eBP appeared more likely to have migraine, and initial analysis using chi-squared test suggested that these differences were significant $(P<0.05)$. There were no significant differences in TTH. Overall (1.9 \% vs $0.7 \%$ ), and in females ( $3.1 \%$ vs $1.0 \%$ ), participants with eBP appeared more likely to have headache on $\geq 15$ days/month, and again initial analysis using chi-squared test suggested that these differences were significant $(p<0.005)$. In all cases, however, AORs from multivariate analysis indicated no significance (Table 3).

Table 2 Demographic, anthropometric and blood pressure data of the sample according to headache type

\begin{tabular}{|c|c|c|c|c|}
\hline Variable & Category & Migraine & Tension-type headache & Headache on $\geq 15 \mathrm{~d} / \mathrm{m}$ \\
\hline \multirow[t]{2}{*}{ Gender } & Male & 150 & 193 & 13 \\
\hline & Female & 316 & 342 & 35 \\
\hline \multirow[t]{2}{*}{ Age (years) } & $18-39$ & 133 & 159 & 6 \\
\hline & $40-65$ & 333 & 376 & 42 \\
\hline \multirow[t]{2}{*}{ Habitation } & Urban & 162 & 209 & 13 \\
\hline & Rural & 304 & 326 & 35 \\
\hline \multirow[t]{2}{*}{ Educational level } & Secondary school or less & 337 & 374 & 43 \\
\hline & Highschool or above & 129 & 161 & 5 \\
\hline \multirow[t]{2}{*}{ Marital status } & Single, widowed, divorced & 31 & 56 & 6 \\
\hline & Married & 435 & 479 & 42 \\
\hline \multirow[t]{2}{*}{ Body weight } & Normal or below & 336 & 387 & 28 \\
\hline & Overweight & 130 & 148 & 20 \\
\hline \multirow[t]{2}{*}{ Occupation } & Unemployed & 40 & 63 & 4 \\
\hline & Working (employee, other) & 426 & 472 & 44 \\
\hline \multirow[t]{2}{*}{ Blood pressure } & Normal & 345 & 405 & 27 \\
\hline & Elevated & 121 & 130 & 21 \\
\hline
\end{tabular}


Table 3 1-year prevalence of headache disorders and associations with elevated blood pressure

\begin{tabular}{|c|c|c|c|c|c|c|}
\hline \multirow[t]{3}{*}{ Participating sample } & \multicolumn{6}{|c|}{ Prevalence } \\
\hline & \multicolumn{2}{|c|}{ Migraine } & \multicolumn{2}{|c|}{ Tension-type headache } & \multicolumn{2}{|c|}{ Headache on $\geq 15$ days/month } \\
\hline & $n$ & $\%(95 \% \mathrm{Cl})$ & $n$ & $\%(95 \% \mathrm{Cl})$ & $n$ & $\%(95 \% \mathrm{Cl})$ \\
\hline \multicolumn{7}{|l|}{ All $(N=4,987)$} \\
\hline Normal BP $(n=3,885)$ (reference) & 345 & 8.9(8.0-9.8) & 405 & 10.4(9.4-11.4) & 27 & $0.7(0.4-1.0)$ \\
\hline Elevated BP $(n=1,102)$ & 121 & 11.0(9.2-12.8) & 130 & 11.8(9.9-13.7) & 21 & $1.9(1.1-2.7)$ \\
\hline Total & 466 & $9.3(8.5-10.2)$ & 535 & 10.7(9.9-11.6) & 48 & $1.0(0.7-1.2)$ \\
\hline Chi-squared & \multicolumn{2}{|c|}{4.468} & \multicolumn{2}{|c|}{1.687} & \multicolumn{2}{|c|}{13.200} \\
\hline$P$ & \multicolumn{2}{|c|}{0.035} & \multicolumn{2}{|c|}{0.194} & \multicolumn{2}{|c|}{0.000} \\
\hline OR $(95 \% \mathrm{Cl})$ & \multicolumn{2}{|c|}{$1.3(1.0-1.6)$} & \multicolumn{2}{|c|}{$1.1(0.9-1.4)$} & \multicolumn{2}{|c|}{$2.8(1.6-4.9)$} \\
\hline $\mathrm{AOR}(95 \% \mathrm{Cl})$ & \multicolumn{2}{|c|}{$1.1(0.9-1.4)$} & \multicolumn{2}{|c|}{$1.0(0.8-1.3)$} & \multicolumn{2}{|c|}{$1.7(0.9-3.1)$} \\
\hline$P(A O R)$ & \multicolumn{2}{|c|}{0.344} & \multicolumn{2}{|c|}{0.954} & \multicolumn{2}{|c|}{0.103} \\
\hline \multicolumn{7}{|l|}{ Male $(N=2,532)$} \\
\hline Normal BP $(n=1,953)$ (reference) & 104 & $5.3(4.3-6.3)$ & 149 & 7.6(6.4-8.8) & 8 & $0.4(0.1-0.7)$ \\
\hline Elevated BP $(n=579)$ & 46 & $7.9(5.7-10.1)$ & 44 & 7.6(5.4-9.8) & 5 & $0.9(0.1-1.7)$ \\
\hline Total & 150 & $5.9(5.0-6.8)$ & 193 & $7.6(6.6-8.6)$ & 13 & $0.5(0.2-0.8)$ \\
\hline Chi-squared & \multicolumn{2}{|c|}{5.499} & \multicolumn{2}{|c|}{0.001} & \multicolumn{2}{|c|}{1.802} \\
\hline$P$ & \multicolumn{2}{|c|}{0.019} & \multicolumn{2}{|c|}{0.981} & \multicolumn{2}{|c|}{0.180} \\
\hline OR $(95 \% \mathrm{Cl})$ & \multicolumn{2}{|c|}{$1.5(1.1-2.2)$} & \multicolumn{2}{|c|}{$1.0(0.7-1.4)$} & \multicolumn{2}{|c|}{$2.1(0.7-6.5)$} \\
\hline AOR $(95 \% \mathrm{Cl})$ & $1.3(0$ & & $0.8(0$ & & 1.4( & \\
\hline$P(A O R)$ & 0.150 & & 0.280 & & 0.53 & \\
\hline Female $(N=2,455)$ & & & & & & \\
\hline Normal BP $(n=1,932)$ (reference) & 241 & $12.5(11.0-14.0)$ & 256 & 13.3(11.8-14.8) & 19 & $1.0(0.6-1.4)$ \\
\hline Elevated BP $(n=523)$ & 75 & $14.3(11.3-17.3)$ & 86 & 16.4(13.2-19.6) & 16 & $3.1(1.6-4.6)$ \\
\hline Total & 316 & $12.9(11.6-14.2)$ & 342 & 13.9(12.5-15.3) & 35 & $1.4(0.9-1.9)$ \\
\hline Chi-squared & 1.278 & & 3.500 & & 12.6 & \\
\hline$P$ & 0.258 & & 0.061 & & 0.00 & \\
\hline OR $(95 \%$ Cl) & $1.2(0$ & & 1.3 & & 3.2 & \\
\hline AOR (95 \% Cl) & $1.0(0$ & & $1.2(C$ & & 1.7 & \\
\hline$P(A O R)$ & 0.852 & & 0.311 & & 0.14 & \\
\hline
\end{tabular}

$A O R$ : adjusted odds ratio; $B P$ : blood pressure; $C l$ : confidence interval; $O R$ : odds ratio

The associations of demographic and anthropometric variables with eBP are shown in Table 4. The strongest associations surviving multivariate analysis were higher age (AOR 3.7) and being overweight (AOR 2.4), and these were seen in both genders. Male gender was also significantly associated, although not very strongly. Lower educational level was a weak but significant factor overall and in females, and urban habitation was similar overall and in males (Table 4).

\section{Discussion}

This large population-based study in Mainland China estimated the prevalence of primary headache disorders [4] and, opportunistically, the adult prevalence of eBP. It had multiple strengths: we recruited a large sample of 5,000 nationwide, inclusive of China's ethnic, cultural and geographical diversities, promoted data quality by engaging participants in face-to-face interviews and limited bias by achieving a participation rate of well over $90 \%$. We used a validated questionnaire for headache diagnosis [15]. We measured BP in participants' own homes, using a standardised procedure. Because of the cross-sectional design of the study, we would not be able to establish causation in any associations that might be observed, but this did not prove to be a limitation. It was, of course, a limitation that we could not collect information about antihypertensive treatments, but we designed the study around that.

The data on headache prevalence have been reported elsewhere [4]. Here we note a prevalence of eBP of $22.1 \%$, slightly and non-significantly higher in males than females (although multivariate analysis detected a 
Table 4 Elevated blood pressure and its associations with demographic and anthropometric variables, overall and by gender

\begin{tabular}{|c|c|c|c|c|}
\hline Variables & $\mathrm{OR}(95 \% \mathrm{Cl})^{\mathrm{a}}$ & P & AOR $(95 \% C l)^{a}$ & P \\
\hline \multicolumn{5}{|l|}{ All $(N=4,987)$} \\
\hline Female gender & $0.9(0.8-1.0)$ & 0.183 & $0.8(0.7-1.0)$ & 0.014 \\
\hline Higher age & $4.3(3.6-5.1)$ & 0.000 & $3.7(3.1-4.4)$ & 0.000 \\
\hline Rural habitation & $0.8(0.7-1.0)$ & 0.012 & $0.8(0.7-0.9)$ & 0.009 \\
\hline Better educated & $0.6(0.5-0.7)$ & 0.000 & $0.7(0.6-0.9)$ & 0.000 \\
\hline Married & $2.1(1.7-2.7)$ & 0.000 & $1.1(0.9-1.5)$ & 0.356 \\
\hline Overweight & $2.8(2.4-3.2)$ & 0.000 & $2.4(2.1-2.8)$ & 0.000 \\
\hline Working & $0.9(0.7-1.1)$ & 0.175 & $0.9(0.7-1.2)$ & 0.507 \\
\hline \multicolumn{5}{|l|}{ Male $(N=2,532)$} \\
\hline Higher age & $3.6(2.8-4.5)$ & 0.000 & $3.2(2.5-4.0)$ & 0.000 \\
\hline Rural habitation & $0.7(0.6-0.9)$ & 0.002 & $0.7(0.6-0.9)$ & 0.008 \\
\hline Better educated & $0.9(0.7-1.1)$ & 0.159 & $0.9(0.7-1.1)$ & 0.273 \\
\hline Married & $2.8(2.0-3.9)$ & 0.000 & $1.5(1.0-2.2)$ & 0.031 \\
\hline Overweight & $2.4(2.0-2.9)$ & 0.000 & $2.3(1.8-2.8)$ & 0.000 \\
\hline Working & $1.1(0.7-1.6)$ & 0.757 & $1.2(0.8-1.8)$ & 0.492 \\
\hline \multicolumn{5}{|l|}{ Female $(N=2,455)$} \\
\hline Higher age & $5.4(4.1-7.1)$ & 0.000 & $4.2(3.2-5.6)$ & 0.000 \\
\hline Rural habitation & $0.9(0.8-1.2)$ & 0.615 & $0.9(0.7-1.1)$ & 0.215 \\
\hline Better educated & $0.4(0.3-0.5)$ & 0.000 & $0.5(0.4-0.7)$ & 0.000 \\
\hline Married & $1.6(1.1-2.2)$ & 0.007 & $0.9(0.6-1.2)$ & 0.420 \\
\hline Overweight & $3.2(2.6-3.9)$ & 0.000 & $2.5(2.0-3.1)$ & 0.000 \\
\hline Working & $0.7(0.5-1.0)$ & 0.031 & $0.8(0.6-1.1)$ & 0.219 \\
\hline
\end{tabular}

$A O R$ : adjusted odds ratio; $B P$ : blood pressure; $C l$ : confidence interval; $O R$ : odds ratio

${ }^{\text {a }}$ References groups for each of the variables are the alternative categories shown in Tables 1 and 2

weak but significant association of eBP with male gender). This may be considered to accord with the recently reported adult prevalence of HTN in China of $26.6 \%$ [5], but we discuss this later. First we observe that there were no clear associations between eBP and headache. The weak association between eBP and migraine overall and in males (OR 1.3-1.5) did not survive multivariate analysis. An apparently stronger association with headache on $\geq 15$ days/month (OR 2.1-3.2) was never significant in males and again did not survive multivariate analysis. The confounding effects of age and being overweight - both risk factors for frequent headache [24, 25] and, as we showed, both strongly (and probably causally) associated with eBP were at work here.

In this regard our findings were in line with most of those from previous studies. Cirillo et al. [17] found that patients with severe headache had a significantly higher prevalence of HTN, but this study is of limited relevance because of the obvious selection bias. Pietrini et al. [18] found that the prevalence of HTN was higher in all headache disorders, including migraine, TTH and "chronic daily headache", but conducted their study in headache centre outpatients so again there was inevitable selection bias. Neither study employed multivariate adjusted analyses. On the other hand, Waters et al. [9] and Rasmussen et al. [10] both found no association between headache disorders and HTN, although in the latter study DBP was significantly higher in women with migraine than in women without [10]. Using ambulatory BP monitoring, Kruszewski et al. [12] and Gus et al. [11] found that active headache was not associated with simultaneous $\mathrm{eBP}$ in patients with mild-tomoderate HTN. Some studies suggested inverse relationships. Wiehe et al. [15] found that individuals with normal $\mathrm{BP}$ complained of migraine more frequently than those with high-normal BP or HTN, while Tzourio et al. [14] found migraine in the elderly was associated with lower levels of BP. Goulart et al. [13] reported an inverse association between HTN and migraine in men but not in women. An inverse relationship between BP and probability of subsequently developing headache was confirmed in the HUNT study, a large-scale Norwegian population-based cohort survey [16].

In summary, most studies - many of which were wellperformed - do not suggest significant associations between headache and HTN, and our findings from this large study do not do so either. Our analyses noted the effects of confounding factors, and illustrate the importance of multivariate analysis, lack of which may at least partially explain the inconsistent results of previous studies. However, it must be remembered that what we observed by recording eBP was not the prevalence of HTN but, essentially, that of untreated or undertreated HTN.

Which brings us back to the issue of public-health concern: that $22.1 \%$ of the Chinese population aged 18-65 years have eBP regardless of any treatment being taken. Associations with higher age, being overweight and, perhaps, lower educational level are unsurprising; the effect of urban habitation, we guess, is mediated through unhealthy living. But the key point is this: while the prevalence of HTN in China may be $26.6 \%$ [3], and HTN is one of the major risk factors for CVDs, which are themselves leading causes of mortality especially in low- and middle-income countries [2], our observation suggests that only one in six affected adults are adequately treated. This ought to be taken very seriously, and the reasons discovered: do the failures lie in diagnosis, health-care coverage, health care itself (wrong treatments) or patientadherence? Whatever the cause(s), it is clear evidence of unmet health-care need.

\section{Conclusion}

In conclusion, we found no clear-cut associations between eBP and any headache disorder. We did find an alarmingly 
high prevalence of eBP, recognizing that this signals substantial under-treatment of a serious condition.

\section{Competing interests}

The authors declare that they have no competing interests.

\section{Authors' contributions}

SY and TS conceived the study, and SY organized the national survey. MH did the statistic analysis and drafted the manuscript. RL, XY, GZ, XQ, JF, YF participated in the design and coordination of the study, and the data collection of patients. XC did sample selection and helped statistic analysis work, and TS helped to draft and revise the manuscript. All authors read and approved the final manuscript.

\section{Acknowledgments}

This study was supported by Lifting The Burden: the Global Campaign against Headache, and by the Chinese Headache Society. Lifting The Burden is a UK-registered not-for-profit NGO. The paper was written without financial support by any pharmaceutical company or other agency. The authors are grateful for the arduous work of the neurologists, including Hua Bai, Min Chen, Xueying Guo, De'an Jiang, Weiqing Li, Jie Lin, Guohe Liu, Ying Liu, Minfang Lou, Xinming Lou, Yunwen Lou, Haidong Lv, Sha Ma, Haiyun Mei, Xia Shen, Jinping Sun, Ping Sun, Feng Tan, Mingshan Tang, Weiwen Wang, Lianhong Xie, Xionggen Xie, Jiangtao Xu, Jinsheng Yang, Wei Yang, Changjiang Yao, Lin Yin, Tao Yu, Huiying Zhang, Jintao Zhang, Yusen Zhou, Jianguo Zhu and Daliang Zou, and their teams, who took part in performing this nationwide survey.

\section{Author details}

'Department of Neurology, Chinese PLA General Hospital, Fuxing Road 28, Haidian District, 100853 Beijing, China. ${ }^{2}$ Department of Neurology, Xiangya Hospital, Central-South University, Xiangya Road 87, 410008 Changsha, Hunan Province, China. ${ }^{3}$ Department of Neurology, Xijing Hospital, The Fourth Military Medical University, Changle West Road 15, 710032 Xian, Shaanxi Province, China. ${ }^{4}$ Department of Neurology, Affiliated Huashan Hospital of Fudan University, Urumqi Middle Road 12, 200040 Shanghai, China. ${ }^{5}$ Department of Neurology, The First Hospital of Jilin University, Xinmin Street 71, 130021 Changchun, Jilin Province, China. ${ }^{6}$ Department of Neurology, The First Affiliated Hospital of Sun Yat-sen University, The Second Zhongshan Road 58, 510080 Guangzhou, Guangdong Province, China. ${ }^{7}$ Department of Health and Economics, Chinese PLA General Hospital, Fuxing Road 28, Haidian District, 100853 Beijing, China. ${ }^{8}$ Department of Neuroscience, Norwegian University of Science and Technology, Trondheim, Norway.

\section{Received: 21 August 2015 Accepted: 29 September 2015}

Published online: 05 October 2015

\section{References}

1. Kearney PM, Whelton M, Reynolds K, Muntner P, Whelton PK, He J (2005) Global burden of hypertension: analysis of worldwide data. Lancet 365(9455):217-223. doi:10.1016/S0140-6736(05)17741-1.

2. World Health Organization (2010) Global status report on non-communicable diseases. WHO, Geneva.

3. Stovner L, Hagen K, Jensen R, Katsarava Z, Lipton R, Scher A, Steiner T, Zwart JA (2007) The global burden of headache: a documentation of headache prevalence and disability worldwide. Cephalalgia 27(3):193-210. doi:10.1111/j.1468-2982.2007.01288.x

4. Steiner TJ, Birbeck GL, Jensen RH, Katsarava Z, Stovner $L$, Martelletti P (2015) Headache disorders are third cause of disability worldwide. J Headache Pain 16:544. doi:10.1186/s10194-015-0544-2.

5. Gao Y, Chen G, Tian H, Lin L, Lu J, Weng J, Jia W, Ji L, Xiao J, Zhou Z, Ran X, Ren $Y$, Chen T, Yang W (2013) Prevalence of hypertension in china: a crosssectional study. PloS One 8 (6):e65938.

6. Yu S, Liu R, Zhao G, Yang X, Qiao X, Feng J, Fang Y, Cao X, He M, Steiner T (2012) The prevalence and burden of primary headaches in China: a population-based door-to-door survey. Headache 52(4):582-591.

7. Sakai F, Igarashi H (1997) Prevalence of migraine in Japan: a nationwide survey. Cephalalgia 17(1):15-22.

8. Wang SJ, Fuh JL, Young YH, Lu SR, Shia BC (2000) Prevalence of migraine in Taipei, Taiwan: a population-based survey. Cephalalgia 20(6):566-572.
9. Waters WE (1971) Headache and blood pressure in the community. Br Med J 1(5741):142-143.

10. Rasmussen BK, Olesen J (1992) Symptomatic and nonsymptomatic headaches in a general population. Neurology 42(6):1225-1231.

11. Gus M, Fuchs FD, Pimentel M, Rosa D, Melo AG, Moreira LB (2001) Behavior of ambulatory blood pressure surrounding episodes of headache in mildly hypertensive patients. Arch Intern Med 161(2):252-255.

12. Kruszewski P, Bieniaszewski L, Neubauer J, Krupa-Wojciechowska B (2000) Headache in patients with mild to moderate hypertension is generally not associated with simultaneous blood pressure elevation. J Hypertens 18(4):437-444

13. Goulart AC, Santos IS, Lotufo PA, Bensenor IM (2015) Gender aspects of the relationship between migraine and cardiovascular risk factors: A cross-sectional evaluation in the Brazilian Longitudinal Study of Adult Health (ELSA-Brasil). Cephalalgia 11:0333102415570494.

14. Tzourio C, Gagniere B, El Amrani M, Alperovitch A, Bousser MG (2003) Relationship between migraine, blood pressure and carotid thickness. A population-based study in the elderly. Cephalalgia 23(9):914-920.

15. Wiehe M, Fuchs SC, Moreira LB, Moraes RS, Fuchs FD (2002) Migraine is more frequent in individuals with optimal and normal blood pressure: a population-based study. J Hypertens 20(7):1303-1306.

16. Fagernaes CF, Heuch I, Zwart JA, Winsvold BS, Linde M, Hagen K (2015) Blood pressure as a risk factor for headache and migraine: a prospective population-based study. Eur J Neurol 22(1):156-162.

17. Cirillo M, Stellato D, Lombardi C, De Santo NG, Covelli V (1999) Headache and cardiovascular risk factors: positive association with hypertension. Headache 39(6):409-416.

18. Pietrini U, De Luca M, De Santis G (2005) Hypertension in headache patients? A clinical study. Acta Neurol Scand 112(4):259-264.

19. Yu SY, Cao XT, Zhao G, Yang XS, Qiao XY, Fang YN, Feng JC, Liu RZ, Steiner TJ (2011) The burden of headache in China: validation of diagnostic questionnaire for a population-based survey. J Headache Pain 12(2):141-146.

20. Steiner TJ (2004) Lifting the burden: The global campaign against headache. Lancet Neurol 3(4):204-5.

21. International Headache Society (2004) The international classification of headache disorders: 2nd edition. Cephalalgia 24 Suppl 1:9-160.

22. The sixth report of the Joint National Committee on prevention, detection, evaluation, and treatment of high blood pressure (1997). Arch Intern Med 157 (21):2413-2446. http://www.ncbi.n/m.nih.gov/pubmed/?term=The+sixth +report+of-the+joint+national+committee+on+prevention $\% 2 \mathrm{C}$ +detection $\% 2 \mathrm{C}+$ evaluation $\% 2 \mathrm{C}+$ and +treatment+of+high+blood +pressure.Archives+of-Internal+Medicine\%2C+157(21)\%3A2413-2446.

23. Yu S, Liu R, Yang X, Zhao G, Qiao X, Feng J, Fang Y, Cao X, He M, Steiner TJ (2012) Body mass index and migraine: a survey of the Chinese adult population. J Headache Pain 13(7):531-536.

24. Scher Al, Stewart WF, Ricci JA, Lipton RB (2003) Factors associated with the onset and remission of chronic daily headache in a population-based study. Pain 106(1-2):81-89.

25. Bigal ME, Lipton RB (2006) Obesity is a risk factor for transformed migraine but not chronic tension-type headache. Neurology 67(2):252-257.

\section{Submit your manuscript to a SpringerOpen ${ }^{\odot}$ journal and benefit from:}

- Convenient online submission

- Rigorous peer review

- Immediate publication on acceptance

- Open access: articles freely available online

- High visibility within the field

- Retaining the copyright to your article

Submit your next manuscript at $>$ springeropen.com 